\title{
Positive Effect of Vitamin D and Magnesium Supplementation on Mental health Status of Attention-Deficit Hyperactive Children; A Randomized Double blind Controlled Clinical Trial
}

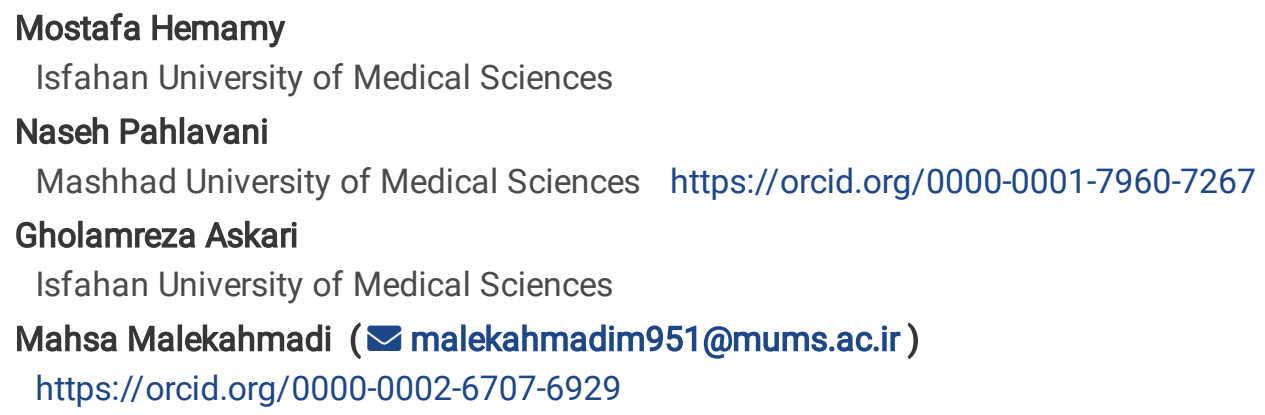

Research article

Keywords: Attention-deficit disorder with hyperactivity, vitamin D, magnesium, supplementation, randomized controlled trial

Posted Date: August 6th, 2020

DOI: https://doi.org/10.21203/rs.3.rs-52324/v1

License: (-) (i) This work is licensed under a Creative Commons Attribution 4.0 International License. Read Full License 


\section{Abstract}

Background: Attention-Deficit / Hyperactivity Disorder (ADHD) is a neurodevelopmental disorder, characterized by varying severity in attention deficit and hyperactivity. Studies have shown deficiencies in the serum level of magnesium and vitamin D in ADHD. The aim of this study is to determine the effect of Vitamin D and magnesium supplementation on mental health in children with ADHD.

Method: This double-blind, randomized controlled trial was performed on 66 ADHD children. participants were randomly allocated to receive both Vitamin D (50,000 IU/week) and magnesium ( $6 \mathrm{mg} / \mathrm{kg} /$ day $)$ supplements $(n=33)$ or placebos $(n=33)$ for 8 weeks. Strengths and difficulties questionnaire were used to evaluate children's mental health at baseline and at the end of the study.

Results: After 8 weeks of intervention, the serum levels of 25-hydroxy-Vitamin D3 and magnesium increased significantly in the intervention group compared with the control group. Also a significant decrease in changes of emotional problems $(p=0.001)$, conduct problems $(p=0.002)$, peer problems $(p=0.001)$, prosocial score $(p=0.007)$, total difficulties $(p=0.001)$, externalizing score $(p=0.001)$, and internalizing score $(p=0.001)$ was seen in intervention group at the end of study.

Conclusion: Vitamin D (50,000 IU/week) and magnesium ( $6 \mathrm{mg} / \mathrm{kg} / \mathrm{day})$ co-supplementation during 8-week could improve the behavioral function and mental health in ADHD. Although further well-designed studies with a larger sample size are needed.

the IRCT registration: IRCT2016030326886N1.

\section{Introduction}

Attention Deficit / Hyperactivity Disorder (ADHD) is characterized by varying severity in attention deficit and hyperactivity. This condition is related to neurodevelopmental disorder. The prevalence of ADHD has been increasing over the past decades (1). $A D H D$ is diagnosed in children with poor academic and social development, learning disabilities, social dysfunction, low selfesteem, and impaired emotion regulation. Many of these symptoms persist into childhood and adulthood leading to decreased quality of life (2-4). In the worldwide, $5-7 \%$ of school-age children have ADHD $(5,6)$. In Iran, $5.03 \%$ of boys and $2.79 \%$ of girls of school age have ADHD (7). The exact cause of ADHD has not yet been identified, and a number of environmental and genetic factors have been studied. For example, a genetic factor related to dopaminergic genotypes exposed to environmental factors, such as maternal smoking before birth, increases the risk of ADHD in children (8). In general, the risk factors for ADHD include: smoking, alcohol and substance abuse and maternal stress during pregnancy, low birth weight and preterm delivery, contaminants such as organophosphates, polychlorinated biphenyls, lead, dye Artificial ores, poor socio-economic status of the family (9). Medications prescribed today have a great effect on improving the symptoms of ADHD, and psychological counseling reinforces this effect. However, a significant number of children with ADHD still show symptoms (10). On the other hand, many parents tend to seek "alternative" or "natural" therapies because of concerns about the side effects of medications. Studies showed that approximately $24.7 \%$ of children with ADHD received some form of complementary and alternative medicine (11).

Nutrient deficiencies have not been shown to cause ADHD in children, but studies have shown deficiencies in some nutrients, such as magnesium and vitamin $D(12,13)$. Evidences have shown that vitamin $D$ plays an important role in the proper functioning of the central nervous system (CNS) and mental health (14-16). Although there is clear evidence that vitamin D levels are lower in children and adolescents with ADHD (17-19), the benefits of vitamin D supplementation in this group are still unclear.

Magnesium is another essential nutrient that is associated with cognitive impairment and can lead to symptoms such as fatigue, lack of concentration, nervousness and mood swings (20). According to a meta-analysis, children and adolescents with ADHD have significantly lower serum magnesium levels than their healthy counterparts (13).

Therefore, the aim of the randomized controlled trial is to determine the effect of Vitamin $D$ and magnesium supplementation on mental health in children with ADHD.

\section{Method}


This is a double-blind randomized controlled trial. During a period of 2.5 months, 74 ADHD children recruited from Clinic of Noor and Ali Asghar of Isfahan University of Medical Sciences. The study was approved by Ethics Committee of Isfahan University of Medical Sciences, Isfahan, Iran. This trial was registered at Iranian Registry of Clinical Trials as IRCT2016030326886N1.

The inclusion criteria included; 1) Diagnosis of ADHD based on the presence of at least 6 out of 9 cases of inattention and also at least 6 out of 9 cases of hyperactivity based on DSM IV (Diagnostic and Statistical Manual of Mental Disorders, fourth edition), 2) Ages between 6-12 years, 3) Serum level of 25-hydroxyvitamin D囚 less than $30 \mathrm{ng} / \mathrm{dL}(21), 4)$ Serum magnesium levels are less than $2.3 \mathrm{mg} / \mathrm{dL}(22), 5)$ Consent to participate in the study. Exclusion criteria included; 1) Suffering from chronic medical or other psychiatric disorders, 2) Taking any multivitamin/mineral before initiating or during study.

In order to observe the ethical considerations, the method and the objectives of the research were explained to each participant and they entered the study with the written consent of their parents or legal guardian. Participants were divided into two groups of intervention and control by randomized double block method after stratification the sex. An independent person made random allocation cards using computer-generated sequence and used sequentially numbered, sealed, opaque envelopes to conceal the allocation. Neither the researcher nor the participants were aware of the groups. Intervention group received pearl of Vitamin D $(50,000 \mathrm{IU} /$ week) and oral tablet of magnesium (6 mg/kg/day) (23). Control group received placebo which were similar in appearance, color, and taste to these supplements. Duration of intervention was 8 weeks. Participant's compliance was measured through compare the serum levels of Vitamin D and magnesium before and after the intervention in two groups (24).

Baseline characteristics of participants were collected by questionnaire. Height and weight was measured with a precision of $0.5 \mathrm{~cm}$ and $100 \mathrm{~g}$ respectively. Body mass index (BMI) was calculated by weight in kilograms divided by height in meters squared. Serum levels of 25-OH-Vitamin D and magnesium were assessed at baseline and at the end of the intervention period. Serum levels of 25-OH-Vitamin D were measured by enzyme-linked immunosorbent assay (ELISA) method with a commercially available ELISA kit from Immundiagnostik AG, Bensheim, Germany. Serum levels of magnesium were measured by an autoanalyzer (Hitachi 917, Roche Diagnostics ${ }^{\circledR} \mathrm{GmbH}$, Mannheim, Germany) using a commercially available kit.

Strength and difficulties questionnaire (SDQ) was used to evaluate mental health status of participants (25) at baseline and at the end of study (8th week). This scoring system contains 25 questions. Each of the five scale of the SDQ are scored from 0-10, and one can add up four of these (emotional, conduct, hyperactivity and peer problems) to create total difficulty score (range 0-40). One can also add the emotional and peer items together to get an internalizing problems score (range 0-20) and add the conduct and hyperactivity questions together to get an externalizing score (range $0-20$ ).

Statistical analysis was performed using descriptive and inferential statistics

Kolmogorov-Smirnov test used to assess normality of variables distribution. To compare intragroup changes Wilcoxon signed-rank test and Mann-Whitney test was applied. Chi-square test was used to assess the significance level of qualitative variables between the two groups. For all analyses, SPSS 19 (SPSS, Inc., Chicago, IL, USA) was used. P= 0.05 considered as significance level.

\section{Results}

Of 74 children screened for this trial, 66 subjects (intervention group $(n=33)$ and control group $n=33)$ ) were selected based on inclusion and exclusion criteria. From 66 patients in the baseline, all participants completed the study (Fig. 1). In our study, more than $95 \%$ of supplements were consumed in both groups and the rate of compliance in present study was high.

Mean age of participants was $9.11 \pm 1.61$ years. The demographic and baseline data of children are shown in Table 1. There was no statistically significant difference in age, weight, height, gender, and Ritalin dose between two groups (Table 1). Moreover, the baseline levels of 25-OH-vitamin D and magnesium were not different between the intervention and control groups (Fig. 2 \&3). After 8-week intervention the serum levels of $25-\mathrm{OH}$-Vitamin $\mathrm{D}$ and magnesium significantly increased in intervention group compared to placebo (Fig. $2 \& 3$ ). 
Table 1

General characteristics of the study participants 1

\begin{tabular}{|c|c|c|c|}
\hline & $\begin{array}{l}\text { Intervention } \\
(\mathrm{n}=33)\end{array}$ & $\begin{array}{l}\text { Control (n } \\
=33)\end{array}$ & $\mathrm{P}^{2}$ \\
\hline Age (years) & $9.06 \pm 1.76$ & $9.15 \pm 1.46$ & 0.80 \\
\hline Weight (kg) & $\begin{array}{l}31.33 \pm \\
9.93\end{array}$ & $\begin{array}{l}31.17 \pm \\
8.82\end{array}$ & 0.96 \\
\hline Height (cm) & $\begin{array}{l}129.46 \pm \\
11.12\end{array}$ & $\begin{array}{l}129.34 \pm \\
9.48\end{array}$ & 0.87 \\
\hline $\mathrm{BMI}\left(\mathrm{kg} / \mathrm{m}^{2}\right)$ & & & 0.66 \\
\hline Underweight & $3(9.10 \%)$ & $1(3.00 \%)$ & \\
\hline $\begin{array}{l}\text { Normal } \\
\text { weight }\end{array}$ & $17(51.50 \%)$ & $21(63.60 \%)$ & \\
\hline Overweight & $8(24.20 \%)$ & $7(21.20 \%)$ & \\
\hline Obese & $5(15.20 \%)$ & $4(12.10 \%)$ & \\
\hline Sex & & & 0.99 \\
\hline Boy (\%) & 23(69.7\%) & 23(69.7\%) & \\
\hline Girl (\%) & $10(30.3 \%)$ & $10(30.3 \%)$ & \\
\hline $\begin{array}{l}\text { Ritalin dose } \\
(\mathrm{mg} / \mathrm{kg})\end{array}$ & $\begin{array}{l}31.33 \pm \\
9.93\end{array}$ & $\begin{array}{l}31.21 \pm \\
8.81\end{array}$ & 0.93 \\
\hline
\end{tabular}

${ }^{1}$ Data are presented as Means \pm SD other than those specified.

${ }^{2}$ For comparison of numerical values mannwhitney test and for qualitative values chi-square test has been used.

Table 2.The effect of vitamin $\mathrm{D}$ and magnesium supplementation compared with placebo on behavior in children with ADHD based on Strengths and difficulties questionnaire ${ }^{1}$

\begin{tabular}{|c|c|c|c|c|c|c|c|c|c|}
\hline \multirow[t]{2}{*}{ Scales } & \multicolumn{3}{|c|}{ Intervention $(\mathrm{n}=33)$} & \multicolumn{4}{|c|}{ Control $(n=33)$} & \multirow[b]{2}{*}{$\mathrm{P}^{4}$} & \multirow[b]{2}{*}{$\mathrm{P}^{5}$} \\
\hline & Baseline & $\begin{array}{l}\text { 8th } \\
\text { week }\end{array}$ & Change $^{2}$ & Baseline & $\begin{array}{l}\text { 8th } \\
\text { week }\end{array}$ & Change $^{2}$ & $P^{3}$ & & \\
\hline Emotional problems score & $4.58 \pm 0.48$ & $\begin{array}{l}3.42 \\
\pm 0.37\end{array}$ & $\begin{array}{l}-1.15 \pm \\
0.34\end{array}$ & $\begin{array}{l}4.70 \pm \\
0.46\end{array}$ & $\begin{array}{l}4.76 \\
\pm 0.44\end{array}$ & $\begin{array}{l}0.06 \pm \\
0.08\end{array}$ & 0.86 & 0.03 & 0.001 \\
\hline Conduct problems score & $4.36 \pm 0.37$ & $\begin{array}{l}3.58 \\
\pm 0.31\end{array}$ & $\begin{array}{l}-0.78 \pm \\
0.24\end{array}$ & $\begin{array}{l}4.42 \pm \\
0.36\end{array}$ & $\begin{array}{l}4.39 \\
\pm 0.36\end{array}$ & $\begin{array}{l}-0.03 \pm \\
0.10\end{array}$ & 0.84 & 0.06 & 0.002 \\
\hline Hyperactivity score & $6.64 \pm 0.29$ & $\begin{array}{l}6.36 \\
\pm 0.30\end{array}$ & $\begin{array}{l}-0.27 \pm \\
0.15\end{array}$ & $\begin{array}{l}6.79 \pm \\
0.30\end{array}$ & $\begin{array}{l}6.85 \\
\pm 0.32\end{array}$ & $\begin{array}{l}0.06 \pm \\
0.07\end{array}$ & 0.70 & 0.15 & 0.08 \\
\hline Peer problems score & $3.73 \pm 0.29$ & $\begin{array}{l}2.67 \\
\pm 0.28\end{array}$ & $\begin{array}{l}-1.06 \pm \\
0.17\end{array}$ & $\begin{array}{l}3.91 \pm \\
0.30\end{array}$ & $\begin{array}{l}3.94 \\
\pm 0.29\end{array}$ & $\begin{array}{l}0.03 \pm \\
0.08\end{array}$ & 0.71 & 0.004 & 0.001 \\
\hline Prosocial score & $7.79 \pm 0.32$ & $\begin{array}{l}7.03 \\
\pm 0.42\end{array}$ & $\begin{array}{l}-0.75 \pm \\
0.25\end{array}$ & $\begin{array}{l}7.70 \pm \\
0.30\end{array}$ & $\begin{array}{l}7.73 \\
\pm 0.29\end{array}$ & $\begin{array}{l}0.03 \pm \\
0.09\end{array}$ & 0.75 & 0.28 & 0.007 \\
\hline Total difficulties score & $\begin{array}{l}19.30 \pm \\
1.06\end{array}$ & $\begin{array}{l}16.03 \\
\pm 0.89\end{array}$ & $\begin{array}{l}-3.27 \pm \\
0.40\end{array}$ & $\begin{array}{l}19.82 \pm \\
1.03\end{array}$ & $\begin{array}{l}19.94 \\
\pm 1.00\end{array}$ & $\begin{array}{l}0.12 \pm \\
0.17\end{array}$ & 0.67 & 0.002 & 0.001 \\
\hline Externalizing score & $\begin{array}{l}11.00 \pm \\
0.61\end{array}$ & $\begin{array}{l}9.94 \\
\pm 0.50\end{array}$ & $\begin{array}{l}-1.06 \pm \\
0.28\end{array}$ & $\begin{array}{l}11.21 \pm \\
0.60\end{array}$ & $\begin{array}{l}11.24 \\
\pm 0.61\end{array}$ & $\begin{array}{l}0.03 \pm \\
0.13\end{array}$ & 0.69 & 0.01 & 0.001 \\
\hline
\end{tabular}




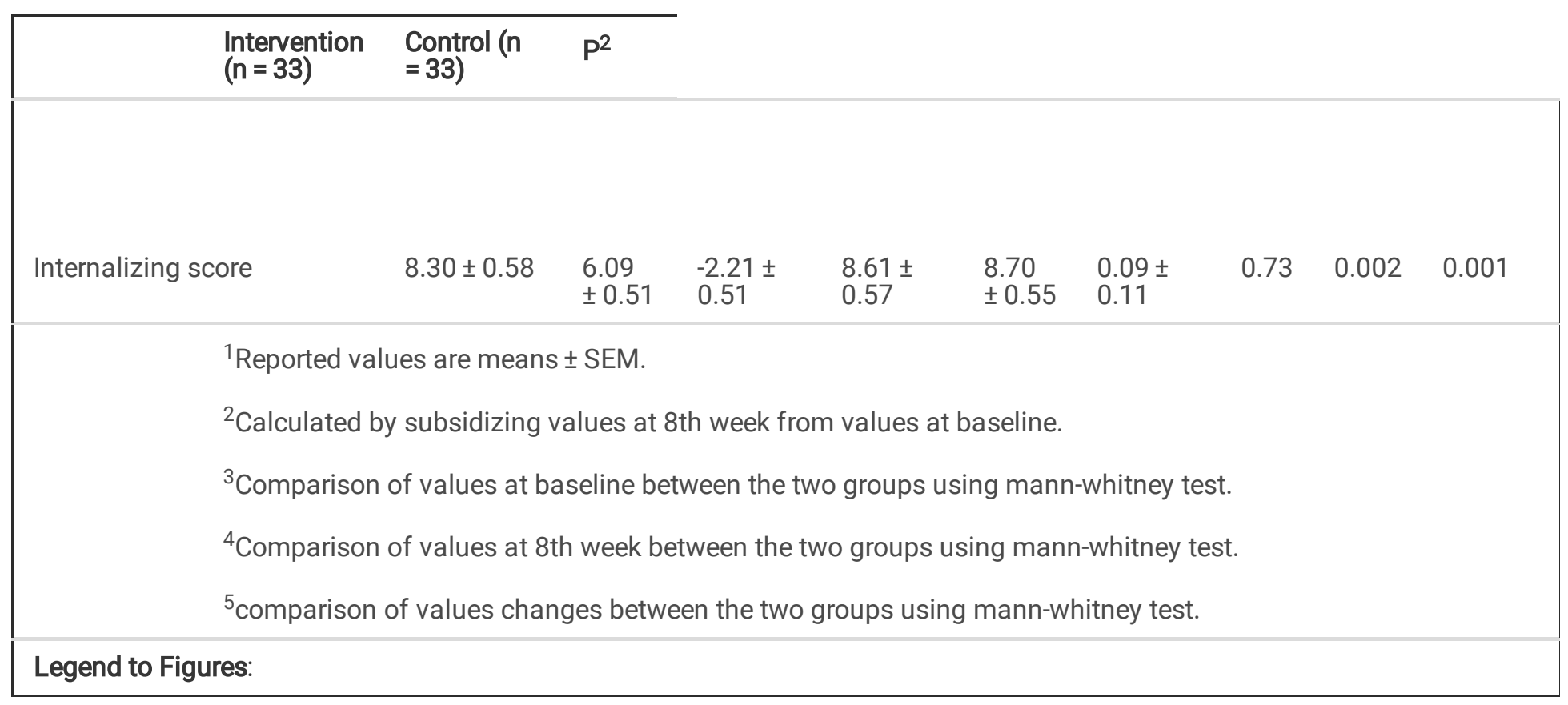

In comparison with the baseline values, a significant decrease in changes of emotional problems score $(p=0.001)$, conduct problems score $(p=0.002)$, peer problems score $(p=0.001)$, prosocial score $(p=0.007)$, total difficulties score $(p=0.001)$, externalizing score $(p=0.001)$, and internalizing score $(p=0.001)$ was seen in intervention group at the end of study, but these changes was not significant for hyperactivity score $(p=0.08)$ compared with changes in placebo group. (Table 2$)$.

\section{Discussion}

To the best of our knowledge, the present study is one of few studies to examine the effect of vitamin $D$ and magnesium supplementation in Iranian ADHD children and results showed that two supplements could decreased emotional, conduct and peer problems, prosocial, total difficulties, externalizing, and internalizing scores compared to placebo consumption, however, did not significantly affect of hyperactivity scores.

ADHD as a common psychiatric disorder among children influenced by genetics and the environment factors (for example nutritional factors such as vitamin $D$ and magnesium). ADHD has three symptoms including impulsivity, hyperactivity, and lack of attention $(26,27)$. Recent studies have shown that serum vitamin D levels in ADHD children are significantly lower than healthy individuals $(28,29)$, and it has also been shown that about $72 \%$ of children with ADHD have magnesium deficiency (30). Elshorbagy et al. study showed that Vitamin D Supplementation in ADHD patients improve cognitive functions such as conceptual level, inattention, opposition, hyperactivity, and impulsivity domains compared to control group that these results confirm the findings of our study (29). Experimental studies in rats have shown that vitamin D deficiency impairs brain distortion, decreased release of neuronal growth factors, sensitivity to psychiatric stimulants (NMDA antagonist MK-801), and impaired attention processing (31), also they have increased impulsivity as well as a lack of inhibitory control (32). In addition, prenatal vitamin $D$ deficiency leads to changes in genes associated with neuronal survival, speech and language, and dopamine synthesis (33). Vitamin D regulates calcium transient in the brain and nerve growth by involving in migration and nerve growth. Separation; Neurotransmission; Cell interaction; and synaptic function. It also protects neural system from reactive oxygen species, alters neuronal factors and monoamine levels, and regulates hormonal and serotonin pathways in the CNS (34). Vitamin D arrange the Wnt/beta-catenin signaling pathway that has role in early brain development by developing the expression of DKK-1 which inhibits the Wnt/beta-catenin signaling pathway (12). Vitamin D is also involved in the synthesis of serotonin (12). All the mentioned mechanisms can explain the reason for the improvement of parameters related to mental health with vitamin supplementation in this study.

On the other hand, magnesium supplementation ( $200 \mathrm{mg} /$ day) for 6 months independently of other mental disorders coexisting with hyperactivity, significantly decreased hyperactivity compared to the control group and their clinical state before supplementation (35). Therapy contains magnesium led to improvements in the behavior, both large- and small-scale mobility, 
decreased the level of anxiety and aggression, increased the attention, corrected with improvement of the magnesium homeostasis (36). These are consistent with our findings. Magnesium is involved in the pathogenesis of ADHD through various molecular mechanisms. Magnesium is an essential substance in the body and plays an important role in biochemical and physiological neurological processes and controls the pathway of glutamate $\mathrm{N}$-methyl aspartate (a stimulant that induces neurotoxicity) (37). Many studies have also shown that magnesium plays a key role in the conversion of essential fatty acids to long-chain omega-3 and omega- 6 fatty acids as cofactors for desaturase enzymes (38). Therefore, its deficiency causes brain dysfunction.

There were several limitations. In this study, the effect of each supplement was not studied separately and the combined effect of magnesium and vitamin D was investigated, this could be due to our small sample size. Future studies should be designed to determine both the combined and the separate effect of each of these micronutrients on the ADHD. Also, dietary intakes of magnesium and Vitamin D as important cofounders, were not assessed and duration of follow-up was short so, long-term effects have not been studied. In addition, participants with with low serum levels of these two micronutrients were included in the study, so it is unclear whether supplementation can be effective in patients with ADHD who are not deficient.

\section{Conclusion}

Vitamin D (50,000 IU/week) and magnesium (6 mg/kg/day) co-supplementation during 8-week could improve the behavioral function and mental health in ADHD children with low serum level of vitamin D and magnesium. Although further well designed studies with a larger sample size are needed to shed light our findings and determine whether vitamin $D$ and magnesium deficiency are the result of ADHD or whether they are risk factors for this disorder.

\section{Declarations}

\section{Authors' contributions}

The authors' responsibilities were as follows. MH, NP, GRA, and MM: designed the trial; MH, NP, and MM wrote the manuscript; GRA and MH designed table and figures; and MH, NP, and MM participated in the drafting and editing of the manuscript. All of the authors read and approved the final manuscript.

\section{Acknowledgments}

The authors take thankful pleasure in acknowledging the unsparing assistance of all participants. This study was extracted from MSc thesis which was approved by the School of Nutrition and Food Science, Isfahan University of Medical Sciences (code: IR. MUI. REC.1394.3.961).

\section{Ethics approval and consent to participate}

Central ethical approval has been confirmed from the Research Ethics Committees of the Isfahan University of medical sciences. All study procedures were in accordance with the ethical standards of the Declaration of Helsinki. Informed consent obtained from all study participants and their guardians.

\section{Consent for publication}

Not applicable

\section{Availability of data and materials}

The datasets used and analyzed during the current study are available from the corresponding author on reasonable request

\section{Financial support and sponsorship}

Funding source of this study was supported by Isfahan University of Medical Sciences. 


\section{Conflicts of interest}

There are no conflicts of interest.

\section{References}

1. Villagomez A, Ramtekkar U. Iron, Magnesium VD. and Zinc Deficiencies in Children Presenting with Symptoms of AttentionDeficit/Hyperactivity Disorder. Children (Basel Switzerland). 2014;1(3):261-79.

2. Döpfner M, Hautmann C, Görtz-Dorten A, Klasen F, Ravens-Sieberer U, Group BS. Long-term course of ADHD symptoms from childhood to early adulthood in a community sample. Eur Child Adolesc Psychiatry. 2015;24(6):665-73.

3. Coghill D, Hodgkins P. Health-related quality of life of children with attention-deficit/hyperactivity disorder versus children with diabetes and healthy controls. European Child Adolescent Psychiatry. 2016;25(3):261-71.

4. Mulraney M, Giallo R, Sciberras E, Lycett K, Mensah F, Coghill D. ADHD symptoms and quality of life across a 12-month period in children with ADHD: A longitudinal study. J Atten Disord. 2019;23(13):1675-85.

5. Thomas R, Sanders S, Doust J, Beller E, Glasziou P. Prevalence of attention-deficit/hyperactivity disorder: a systematic review and meta-analysis. Pediatrics. 2015;135(4):e994-1001.

6. Polanczyk GV, Willcutt EG, Salum GA, Kieling C, Rohde LA. ADHD prevalence estimates across three decades: an updated systematic review and meta-regression analysis. Int J Epidemiol. 2014;43(2):434-42.

7. Mohammadi MR, Ahmadi N, Kamali K, Khaleghi A, Ahmadi A. Epidemiology of psychiatric disorders in iranian children and adolescents (IRCAP) and its relationship with social capital, life style and parents' personality disorders: study protocol. Iranian journal of psychiatry. 2017;12(1):66.

8. Neuman RJ, Lobos E, Reich W, Henderson CA, Sun L-W, Todd RD. Prenatal smoking exposure and dopaminergic genotypes interact to cause a severe ADHD subtype. Biol Psychiatry. 2007;61(12):1320-8.

9. Thapar A, Cooper M, Eyre O, Langley K. Practitioner review: what have we learnt about the causes of ADHD? J Child Psychol Psychiatry. 2013;54(1):3-16.

10. Swanson JM, Kraemer HC, Hinshaw SP, Arnold LE, Conners CK, Abikoff HB, et al. Clinical relevance of the primary findings of the MTA: success rates based on severity of ADHD and ODD symptoms at the end of treatment. Journal of the American Academy of Child Adolescent Psychiatry. 2001;40(2):168-79.

11. Kemper KJ, Gardiner P, Birdee GS. Use of complementary and alternative medical therapies among youth with mental health concerns. Academic pediatrics. 2013;13(6):540-5.

12. Kotsi E, Kotsi E, Perrea DN. Vitamin D levels in children and adolescents with attention-deficit hyperactivity disorder (ADHD): a meta-analysis. Attention deficit hyperactivity disorders. 2019;11(3):221-32.

13. Effatpanah M, Rezaei M, Effatpanah H, Effatpanah Z, Varkaneh HK, Mousavi SM, et al. Magnesium status and attention deficit hyperactivity disorder (ADHD): A meta-analysis. Psychiatry research. 2019;274:228-34.

14. Eyles DW, Burne TH, McGrath JJ. Vitamin D. effects on brain development, adult brain function and the links between low levels of vitamin D and neuropsychiatric disease. Front Neuroendocr. 2013;34(1):47-64.

15. Kaneko I, Sabir MS, Dussik CM, Whitfield GK, Karrys A, Hsieh JC, et al. 1, 25-Dihydroxyvitamin D regulates expression of the tryptophan hydroxylase 2 and leptin genes: implication for behavioral influences of vitamin D. FASEB J. 2015;29(9):4023-35.

16. Autier P, Boniol M, Pizot C, Mullie P. Vitamin D status and ill health: a systematic review. The lancet Diabetes endocrinology. 2014;2(1):76-89.

17. Garipardic M, Doğan M, Bala KA, Mutluer T, Kaba S, Aslan O, et al. Association of attention deficit hyperactivity disorder and autism spectrum disorders with mean platelet volume and vitamin D. Medical science monitor: international medical journal of experimental clinical research. 2017;23:1378.

18. Meyer T, Becker A, Sundermann J, Rothenberger A, Herrmann-Lingen C. Attention deficit-hyperactivity disorder is associated with reduced blood pressure and serum vitamin D levels: results from the nationwide German Health Interview and Examination Survey for Children and Adolescents (KiGGS). Eur Child Adolesc Psychiatry. 2017;26(2):165-75. 
19. Bala KA, Doğan M, Kaba S, Mutluer T, Aslan O, Doğan SZ. Hormone disorder and vitamin deficiency in attention deficit hyperactivity disorder (ADHD) and autism spectrum disorders (ASDs). J Pediatr Endocrinol Metab. 2016;29(9):1077-82.

20. Huss M, Völp A, Stauss-Grabo M. Supplementation of polyunsaturated fatty acids, magnesium and zinc in children seeking medical advice for attention-deficit/hyperactivity problems-an observational cohort study. Lipids Health Dis. 2010;9(1):105.

21. Holick MF, Vitamin D. Physiology, molecular biology, and clinical applications. Vitamin D and Health: evolution, biologic functions, and recommended dietary intakes for vitamin D Totowa: Humana Press Inc. 2009:3-35.

22. Drueke T, Lacour B. Magnesium homeostasis and disorders of magnesium metabolism. Comprehensive clinical nephrology 3rd ed Philadelphia: Mosby. 2007:136-8.

23. Gröber U, Schmidt J, Kisters K. Magnesium in prevention and therapy. Nutrients. 2015;7(9):8199-226.

24. Zhang Z, Peluso MJ, Gross CP, Viscoli CM, Kernan WN. Adherence reporting in randomized controlled trials. Clinical trials. 2014;11(2):195-204.

25. Hall CL, Guo B, Valentine AZ, Groom MJ, Daley D, Sayal K, et al. The validity of the Strengths and Difficulties Questionnaire (SDQ) for children with ADHD symptoms. PloS one. 2019;14(6):e0218518.

26. Johnson SR, Zelig R, Parker A. Vitamin D Status of Children With Attention-Deficit Hyperactivity Disorder. Topics in Clinical Nutrition. 2020;35(3):222-39.

27. Heilskov Rytter MJ, Andersen LBB, Houmann T, Bilenberg N, Hvolby A, Mølgaard C, et al. Diet in the treatment of ADHD in children-A systematic review of the literature. Nord J Psychiatry. 2015;69(1):1-18.

28. Sharif MR, Madani M, Tabatabaei F, Tabatabaee Z. The relationship between serum vitamin $D$ level and attention deficit hyperactivity disorder. Iranian journal of child neurology. 2015;9(4):48.

29. Elshorbagy HH, Barseem NF, Abdelghani WE, Suliman HAl, Al-Shokary AH, Abdulsamea SE, et al. Impact of vitamin D supplementation on attention-deficit hyperactivity disorder in children. Ann Pharmacother. 2018;52(7):623-31.

30. El Baza F, AlShahawi HA, Zahra S, AbdelHakim RA. Magnesium supplementation in children with attention deficit hyperactivity disorder. Egyptian Journal of Medical Human Genetics. 2016;17(1):63-70.

31. Eyles D, Feron F, Cui X, Kesby J, Harms L, Ko P, et al. Developmental vitamin D deficiency causes abnormal brain development. Psychoneuroendocrinology. 2009;34:247-S57.

32. Turner KM, Young JW, McGrath JJ, Eyles DW, Burne TH. Cognitive performance and response inhibition in developmentally vitamin D (DVD)-deficient rats. Behav Brain Res. 2013;242:47-53.

33. Hawes JE, Tesic D, Whitehouse AJ, Zosky GR, Smith JT, Wyrwoll CS. Maternal vitamin D deficiency alters fetal brain development in the BALB/c mouse. Behav Brain Res. 2015;286:192-200.

34. Cass WA, Smith MP, Peters LE. Calcitriol protects against the dopamine-and serotonin-depleting effects of neurotoxic doses of methamphetamine. Ann N Y Acad Sci. 2006;1074(1):261-71.

35. Starobrat-Hermelin B, Kozielec T. The effects of magnesium physiological supplementation on hyperactivity in children with attention deficit hyperactivity disorder (ADHD). Positive response to magnesium oral loading test. Magnesium research. 1997;10(2):149-56.

36. Nogovitsina OR, Levitina EV. [Effect of MAGNE-B6 on the clinical and biochemical manifestations of the syndrome of attention deficit and hyperactivity in children]. Eksp Klin Farmakol. 2006;69(1):74-7.

37. Lau A, Tymianski M. Glutamate receptors, neurotoxicity and neurodegeneration. Pflügers Archiv-European Journal of Physiology. 2010;460(2):525-42.

38. Antalis CJ, Stevens LJ, Campbell M, Pazdro R, Ericson K, Burgess JR. Omega-3 fatty acid status in attentiondeficit/hyperactivity disorder. Prostaglandins, leukotrienes and essential fatty acids. 2006;75(4-5):299-308.

\section{Figures}




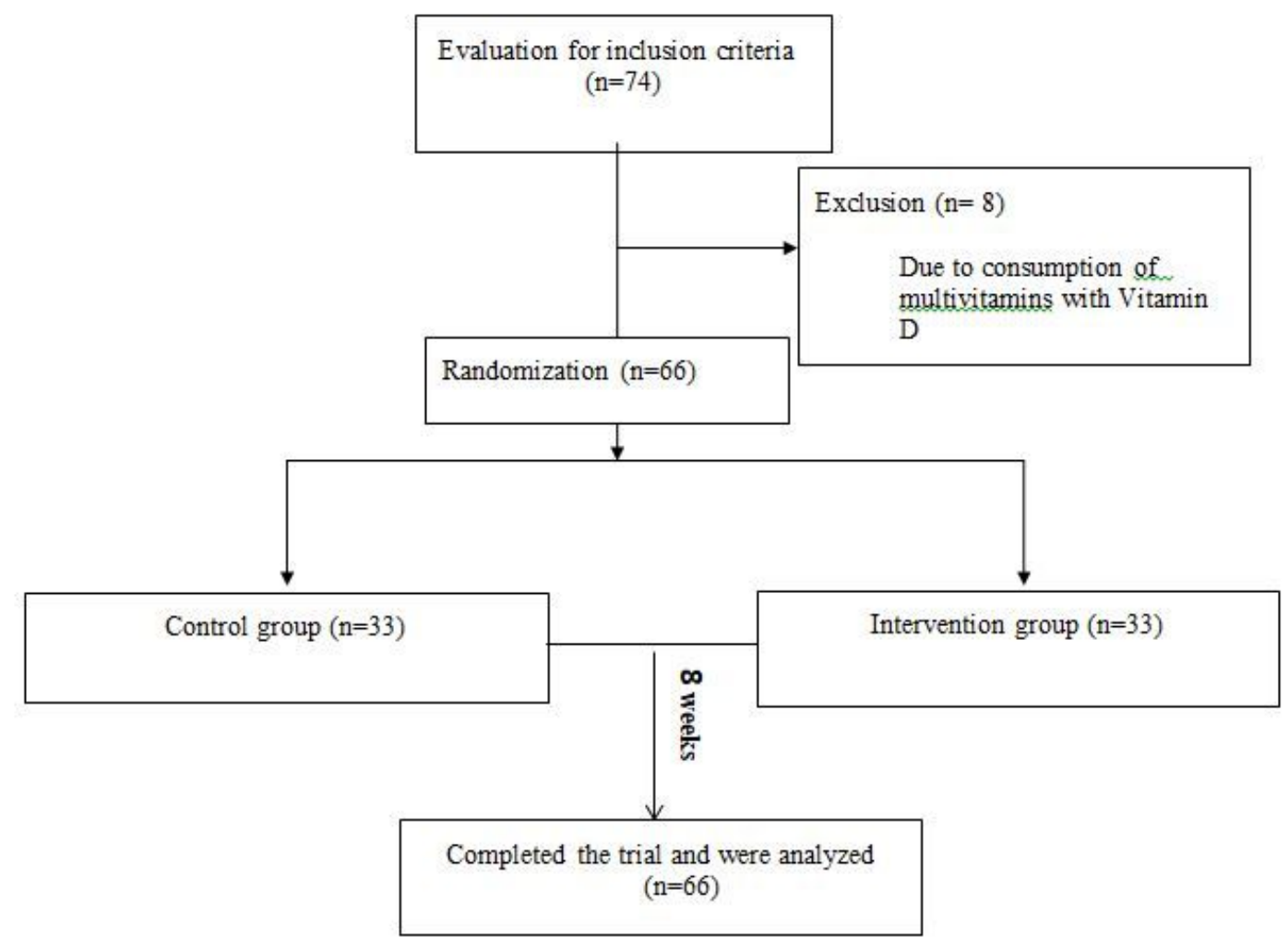

Figure 1

Participants flow diagram

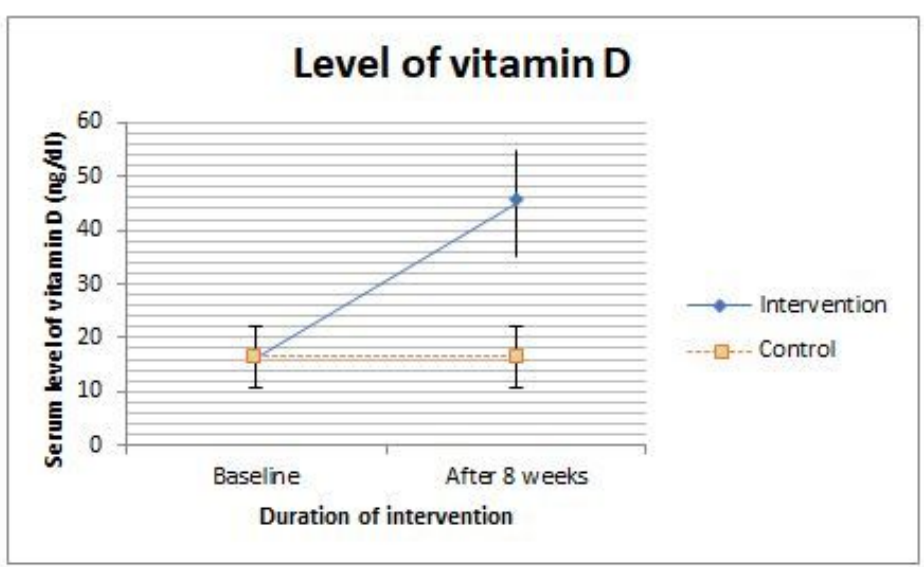

Figure 2

Serum $25-\mathrm{OH}$ vitamin D levels of participants at study baseline and end of trial. P values obtained from independent samples $t$ test. $P$ value for comparison of changes between the two groups was 0.001 . 


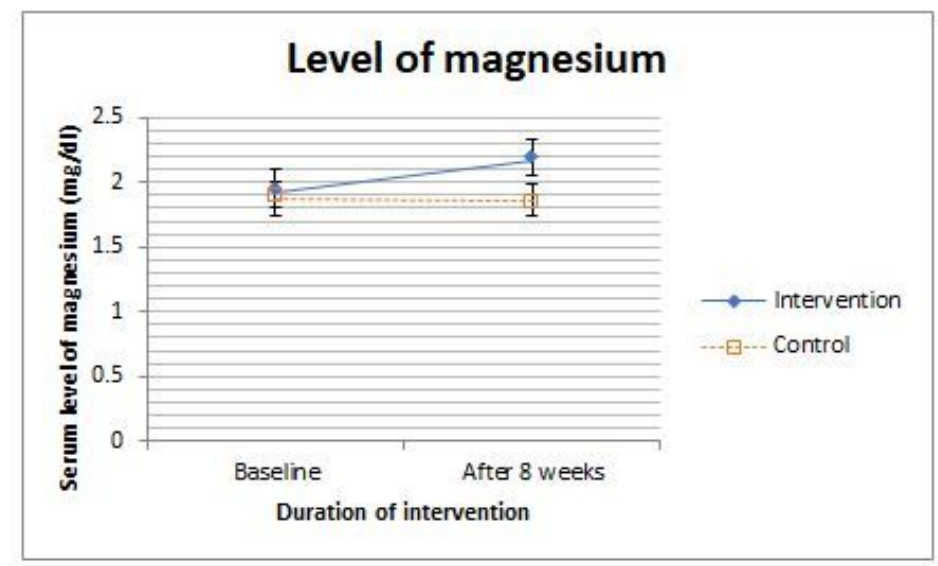

\section{Figure 3}

Serum magnesium levels of participants at study baseline and end of trial. $P$ values obtained from independent samples $t$ test. $P$ value for comparison of changes between the two groups was 0.001 . 